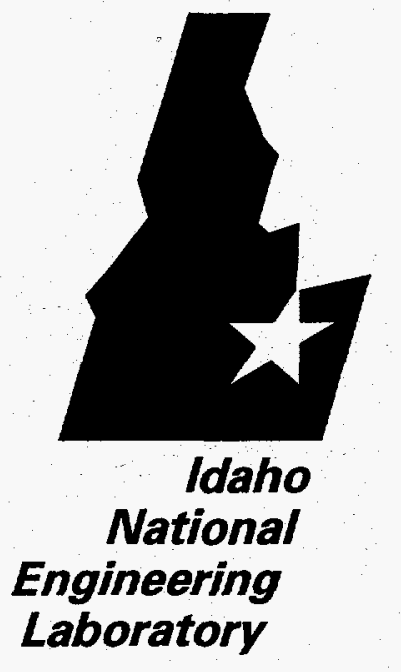

RECEIVED

AUG 211996

OSTI

Transport of Metal Sulfides in Supercritical Carbon Dioxide
W. A. Propp
T. E. Carleson
C. M. Wai
S. Huang

DISTRIBUTION OF THIS DOCUMENT IS UNLIMTES
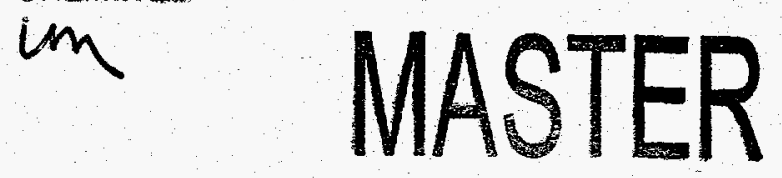

L Lockheed
Idaho Technologles company 


\section{Transport of Metal Sulfides in Supercritical Carbon Dioxide}

W. A. Propp

T. E. Carleson

C. M. Wai

S. Huang

Published May 1996

Idaho National Engineering Laboratory

Lockheed Martin Idaho Technologies Idaho Falls, Idaho 83415

Prepared for the

U.S. Department of the Interior

U.S. Bureau of Mines and for the

U.S. Department of Energy

Under DOE Idaho Operations Office

Contract DE-AC07-94ID13223 


\section{DISCLAIMER}

Portions of this document may be illegible in electronic image products. Images are produced from the best available original document. 


\begin{abstract}
This report presents the results of studies of supercritical fluid extraction of selected organics and of transition metal sulfides using carbon dioxide with and without modifiers. For the metal sulfides, the modifiers water, aqueous EDTA, methanol, and methanolic 2,4-pentanedione (acetyl acetone) were added in amounts ranging from 1 to $10 \mathrm{wt} \%$ depending on the specific modifier used. Extraction efficiency was studied as a function of fluid composition and extraction temperature and pressure. The objective of the work was to investigate the scientific feasibility of using this type of extraction process for metallurgical or environmental applications. Theoretical modeling studies were performed in an attempt to develop predictive capabilities for both solubility calculations and extraction simulation. The experimental studies have established the scientific feasibility of extraction and transport of selected cations by these fluids. Depending on the metal and conditions, transport of up to $12 \%$ of the starting material has been observed; however, the observed extraction efficiencies for inorganics do not approach those typical for organics under similar conditions.
\end{abstract}




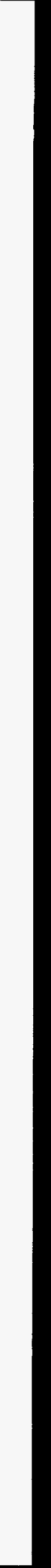




\section{CONTENTS}

ABSTRACT $\ldots \ldots \ldots \ldots \ldots \ldots \ldots \ldots \ldots \ldots \ldots \ldots \ldots \ldots \ldots \ldots \ldots \ldots \ldots \ldots$

INTRODUCTION $\ldots \ldots \ldots \ldots \ldots \ldots \ldots \ldots \ldots \ldots \ldots \ldots \ldots \ldots \ldots \ldots \ldots \ldots$

BACKGROUND $\ldots \ldots \ldots \ldots \ldots \ldots \ldots \ldots \ldots \ldots \ldots \ldots \ldots \ldots \ldots \ldots \ldots$

EXPERIMENTAL PROCEDURES $\ldots \ldots \ldots \ldots \ldots \ldots \ldots \ldots \ldots \ldots \ldots \ldots \ldots \ldots \ldots$

Materials and Experimental Conditions $\ldots \ldots \ldots \ldots \ldots \ldots \ldots \ldots \ldots \ldots \ldots \ldots \ldots$

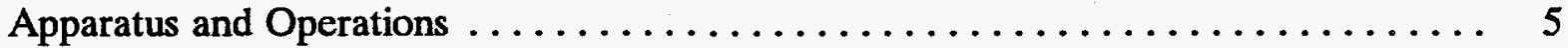

EXPERIMENTAL RESULTS $\ldots \ldots \ldots \ldots \ldots \ldots \ldots \ldots \ldots \ldots \ldots \ldots \ldots \ldots$

DEVELOPMENT OF THEORETICAL BASIS FOR CALCULATING SOLUBILITIES $\ldots 11$

Solubility Calculations $\ldots \ldots \ldots \ldots \ldots \ldots \ldots \ldots \ldots \ldots \ldots \ldots \ldots \ldots \ldots \ldots$

Extraction Simulation $\ldots \ldots \ldots \ldots \ldots \ldots \ldots \ldots \ldots \ldots \ldots \ldots \ldots \ldots \ldots \ldots$

CONCLUSIONS $\ldots \ldots \ldots \ldots \ldots \ldots \ldots \ldots \ldots \ldots \ldots \ldots \ldots \ldots \ldots \ldots \ldots \ldots \ldots$

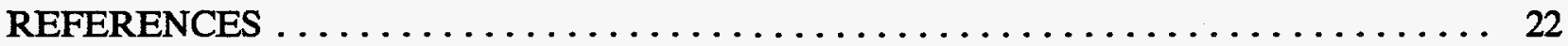

\section{FIGURES}

‡. Supercritical fluid extraction system schematic $\ldots \ldots \ldots \ldots \ldots \ldots \ldots \ldots \ldots$

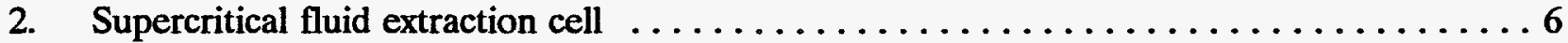

3. Extraction efficiency as a function of temperature for arsenic (top) and fluid density for cadmium (bottom) $\ldots \ldots \ldots \ldots \ldots \ldots \ldots \ldots \ldots \ldots \ldots \ldots \ldots \ldots \ldots \ldots \ldots$

4. Pressure effects on the solubilities of phenanthrene in carbon dioxide $\ldots \ldots \ldots 15$

5. Prediction of the pressure effect on the solubility of cholesterol in carbon dioxide $\ldots \ldots 17$

\section{TABLES}

1. Fluid-critical parameters $\ldots \ldots \ldots \ldots \ldots \ldots \ldots \ldots \ldots \ldots \ldots \ldots \ldots \ldots \ldots$

2. Extraction materials and conditions $\ldots \ldots \ldots \ldots \ldots \ldots \ldots \ldots \ldots \ldots \ldots \ldots$

3. Extraction efficiencies $\ldots \ldots \ldots \ldots \ldots \ldots \ldots \ldots \ldots \ldots \ldots \ldots \ldots \ldots \ldots$ 
4. Typical extraction efficiencies for $\mathrm{CO}_{2}$ and $\mathrm{CO}_{2} / \mathrm{MEOH}$ and for $\mathrm{CO}_{2} / \mathrm{MEOH}$ and $\mathrm{CO}_{2} / \mathrm{MEOH} / \mathrm{ACAC}$ at equivalent conditions

5. Group contributions to interaction constant for organic compound in $\mathrm{CO}_{2} \ldots \ldots \ldots$

6. Estimated $k_{12}$ values for the Peng-Robinson EOS $\ldots \ldots \ldots \ldots \ldots \ldots \ldots$ 


\section{Transport of Metal Sulfides in Supercritical Carbon Dioxide}

\section{INTRODUCTION}

Mining and milling operations generate large quantities of waste containing inorganic and organic hazardous materials. In many cases, the potential exists for these materials to be transported into the environment, producing significant adverse effects. This study investigated the ability of carbon dioxide-based supercritical fluid (SCF) solvent systems to remove hazardous components from residues and from soil in cases where pollution has occurred. The technology has promise for low-volume, concentrated wastes but would have limited applicability for highvolume wastes. However, supercritical fluid extraction, a relatively benign process, may replace existing processes that have high potential environmental impact; for example, gold could be extracted with a supercritical fluid-based process rather than cyanide leaching. Such applications, even though they could involve large volume feedstocks, may be justified by the high unit value of the product or the significant reduction in the environmental impact of the process.

In this project, the SCFs studied for extraction efficiency were unmodified carbon dioxide and carbon dioxide modified with either water or methanol as an entrainer or cosolvent and various ligands as chelating agents for cations. Carbon dioxide was selected as the primary fluid because it is not toxic under normal conditions, not flammable, easy to handle, inexpensive, and supercritical conditions can be achieved at moderate temperatures and pressures, which simplifies handling and equipment. Initially, extraction of selected organics was studied to establish system operating parameters. Following this, extraction of selected transition metal sulfides was studied in detail. The results indicate the possibility of solubilizing metal sulfides in carbon dioxide-based SCFs. Further work in this area is required, but the technique has potential for application in the areas of mining, metallurgy, and environmental remedial action.

\section{BACKGROUND}

An SCF is defined as any fluid that has been raised simultaneously above its critical temperature and pressure. In this region, a single homogeneous phase exists; the fluid is essentially a very dense gas. In general, solubility of a solute is a function of solvent density; the higher the density, the higher the solubility of the solute. The density of a typical SCF is comparable to that of a typical organic liquid and is two to three orders of magnitude larger than that of typical gases. Correspondingly, the solubility of a solute in an SCF is comparable to that observed in organic liquid solvents and significantly higher than that in gases. In addition, SCFs exhibit the unique property of having densities that are sensitive functions of temperature and pressure, particularly in the region close to the critical point. This property allows selective solubilization of solutes by means of relatively small changes in the system temperature or pressure or both. Similar control of solubility is not possible with either normal liquids or gases. This solvent property of SCFs is very attractive for applications involving selective solubilization and separation. 
Supercritical fluid extraction technology is being used commercially in several areas. The criteria used to evaluate this technology for commercial use include small volumes of feedstock, high product unit value, significant health or safety issues associated with alternative methods of processing, a unique product not obtainable through other processes, and significant improvements in overall process efficiency or economics. Applying these criteria, several types of commercial applications of SCFs either have been or are being developed in pharmaceuticals, the food industry, and in extraction of essentials oils. Such applications have been reviewed by various authors. ${ }^{1,2}$

A promising area of research is application of SCFs to environmental problems, such as the treatment of hazardous wastes and various remedial activities. Research in this area has included the extraction of selected organics from solid matrices such as soils. ${ }^{3-5}$ For these studies, the fluid used was carbon dioxide, although in some instances an entrainer such as methanol or toluene was added to modify fluid polarity, thus enhancing solubility. The organics studied as solutes have included the herbicide DDT, toxaphene (an insecticide), and various Aroclors [polychlorinated biphenyls (PCBs)]. The studies determined extraction rate, removal efficiency, and catalytic oxidation of selected solutes in the SCF phase as functions of temperature, pressure, fluid composition, and catalyst. Supercritical water has also been employed as a process medium for the destruction of a wide variety of hazardous organics by oxidation. ${ }^{4-7}$ Destruction efficiencies of greater than $99.99 \%$ are possible for many such wastes. The organic components of the waste are converted to carbon dioxide and water, inorganic constituents are converted to salts that precipitate out, and heteroatoms are converted to the corresponding acid gas for the halides, sulfur, and phosphorous or nitrogen gas in the case of nitrogen or nitro groups. Because wastes are treated in an enclosed system with the processing fluid (water) being recycled, release of pollutants to the environment is eliminated.

Two recent papers ${ }^{7,8}$ have presented a conceptual process flow diagram for a mobile detoxification unit for supercritical extraction of contaminants from soil. Also presented are the results of economic feasibility studies for this unit. Although the process is generic and is not developed in sufficient detail to consider specific contaminants, it is targeted at removal of organics. Finally, Groves et al. ${ }^{9}$ presented an in-depth review of the current technology for the extraction of organic components from hazardous wastes. Topics covered include pertinent aspects of thermodynamics, phase equilibria, kinetics and mass transfer, and related experimental results and applications, including process design and economic information.

There are several significant limitations to the prior work in supercritical fluid extraction of hazardous materials, including:

1. At their present scale, the units have limited throughput.

2. For supercritical water, at least, capital equipment and energy costs are high because of the pressures and temperatures required.

3. In many cases, process efficiency does not meet regulatory requirements for removal or destruction of the hazardous component.

4. To date, there has been little work on either inorganic pollutants or wastes containing both organics and inorganics; the emphasis has been on organic contaminants. 


\section{EXPERIMENTAL PROCEDURES}

\section{Materials and Experimental Conditions}

Supercritical fluid-grade carbon dioxide was used, either alone or with methanol or water as entrainers to increase fluid polarity, enhancing the solubility of nonpolar substances. The carbon dioxide $/ 10 \mathrm{wt} \%$ methanol mixture was obtained commercially. When water was used, the amount calculated to yield $1 \mathrm{wt} \%$ entrainer was injected during the extraction run downstream of the pump (the low concentration of water was set by its limited solubility in carbon dioxide). Table 1 lists the critical parameters for both the pure fluids and the mixtures containing entrainer.

Literature values are shown for the pure components. Parameters for the mixtures were calculated using procedures outlined by Reid et al. ${ }^{10}$ The acentric factor, $\omega$, is a defined constant for the pure components; ${ }^{11}$ a resultant acentric factor was calculated for the mixtures and used in the calculation of the other critical parameters. Because of the low concentrations involved, other constituents, such as chelating agents and inorganic salts, were not considered in the calculation of fluid critical parameters. The purpose of the chelating agents or ligands was to form a stable organometallic complex that would have a significantly higher solubility in the relatively nonpolar fluid than would the uncoordinated cation. This competing equilibrium would provide a mechanism for dissolution of the refractory sulfide matrix and subsequent transport of the metallic species.

The four solid polynuclear aromatic hydrocarbons (PAHs) and four liquid chlorinated hydrocarbons selected as model organic contaminant compounds for initial system testing are listed in Table 2. These particular compounds were chosen because they all have hazardous properties and their previous widespread use has resulted in significant localized environmental pollution. The PAHs are constituents of creosote, and the chlorinated hydrocarbons were commonly used as cleaners and degreasers. Because of the volatility of the liquids, it was necessary to adsorb them on Tenax GC, a packing material used in chromatography, before testing. Individual samples of the solids were weighed directly into the cell.

For the inorganics, serial extractions were performed on aliquots of a mixture composed of eight solids, the sulfides of arsenic, cadmium, cobalt, copper, lead, iron, nickel, and zinc. Sulfides were chosen for study because they are common, particularly those of the environmentally important metals. For these sulfides, extractions consisted of runs using carbon dioxide as the primary fluid, either straight or with the addition of a modifier. The modifiers employed were water, aqueous EDTA, methanol, or methanolic 2,4-pentanedione (acetyl acetone); the term modifier is used to denote the combination of entrainer and ligand.

Table 2 summarizes the extraction conditions used for the various studies. Measurements of system conditions were taken at 5-minute intervals, and modifier was added at 10-minute intervals. For the organics, extraction times ranged from 15 to 60 minutes. For the sulfide extractions, experimental temperatures ranged from ambient to $160^{\circ} \mathrm{C}$, and pressures from 2,400 to $4,800 \mathrm{psig}$, with the specific range of conditions depending on fluid composition. This temperature/pressure range resulted in a fluid density range of $\sim 0.4$ to $1 \mathrm{~g} / \mathrm{mL}$. Fluid flow rates ranged from $\sim 0.3$ to 3 $\mathrm{g} / \mathrm{min}$. Typical extractions lasted 60 minutes, with several serial extractions forming an extraction run. Each extraction in a run was performed at different conditions. Ambient temperature 
Table 1. Fluid-critical parameters.

\begin{tabular}{|c|c|c|c|c|c|c|}
\hline \multirow[b]{2}{*}{ Fluid } & \multicolumn{2}{|c|}{ Critical Pressure, $\mathbf{P}_{c}$} & \multicolumn{2}{|c|}{ Critical Temperature, $\mathrm{T}_{c}$} & \multirow{2}{*}{$\begin{array}{c}\text { Critical } \\
\text { Volume, } V_{c} \\
\left(\mathrm{~cm}^{3} / \mathrm{mol}\right)\end{array}$} & \multirow{2}{*}{$\begin{array}{l}\text { Acentric } \\
\text { factor, } \omega\end{array}$} \\
\hline & (atm) & (psia) & $\left({ }^{\circ} \mathrm{C}\right)$ & $(\mathrm{K})$ & & \\
\hline Carbon dioxide & 72.9 & 1,072 & 31.0 & 304.2 & 94.0 & 0.2250 \\
\hline Water & 218.3 & 3,208 & 374.1 & 647.3 & 57.1 & 0.3440 \\
\hline $\begin{array}{l}\text { Carbon dioxide }+ \\
1 \text { wt } \% \text { water }\end{array}$ & 84.8 & 1,247 & 40.1 & 313.3 & 92.9 & 0.2267 \\
\hline $\begin{array}{l}\text { Carbon dioxide }+ \\
10 \mathrm{wt} \% \text { methanol }\end{array}$ & 101.7 & 1,495 & 73.2 & 346.4 & 99.4 & 0.2570 \\
\hline
\end{tabular}

Table 2. Extraction materials and conditions.

\begin{tabular}{|c|c|c|}
\hline Extraction Mixture & $\begin{array}{l}\text { Temperature Range } \\
\left({ }^{\circ} \mathrm{C}\right)\end{array}$ & $\begin{array}{l}\text { Pressure Range } \\
\text { (psig) }\end{array}$ \\
\hline \multicolumn{3}{|c|}{ Solids - polynuclear aromatic hydrocarbons (PAHs) } \\
\hline Acenaphthene & $34-84$ & $1,921-3,373$ \\
\hline \multicolumn{3}{|l|}{ Naphthalene } \\
\hline \multicolumn{3}{|l|}{ Phenanthrene } \\
\hline \multicolumn{3}{|l|}{ Pyrene } \\
\hline \multicolumn{3}{|c|}{ Liquids - chlorinated hydrocarbons } \\
\hline 1,1,1-trichloroethane (TCA) & $33-38$ & $1,199-1,220$ \\
\hline \multicolumn{3}{|l|}{ Carbon tetrachloride $\left(\mathrm{CCl}_{4}\right)$} \\
\hline \multicolumn{3}{|l|}{ Trichloroethylene (TCE) } \\
\hline \multicolumn{3}{|l|}{ Perchloroethylene (PCE) } \\
\hline \multicolumn{3}{|c|}{ Metal sulfides } \\
\hline $\begin{array}{l}\text { Mixture of sulfides of } \mathrm{As}, \mathrm{Cd}, \mathrm{Co}, \mathrm{Cu}, \mathrm{Pb} \text {, } \\
\mathrm{Fe}, \mathrm{Ni} \text {, and } \mathrm{Zn}\end{array}$ & $15-160$ & $2,400-4,800$ \\
\hline
\end{tabular}


produced subcritical conditions, which were used to determine the effect on extraction of going from subcritical to supercritical. In addition, to compare the results with those obtained by dissolution in liquid water, two serial extractions were carried out using water at ambient temperature and again at $68^{\circ} \mathrm{C}$.

\section{Apparatus and Operations}

The extraction system was designed and fabricated from off-the-shelf high-pressure components. The original system configuration, typical of designs employed elsewhere for similar experiments, used a single high-pressure liquid chromatography (HPLC) pump to pressurize and deliver the fluid and a backpressure regulator (BPR) downstream of the extraction cell to regulate system pressure and provide pressure letdown prior to sample collection. The modifiers were added using a rotary HPLC sample injection valve. A limitation of this system was the potential for precipitation of extracted material within the BPR during letdown. To minimize this problem, the BPR was heated. In addition, the lines were flushed downstream of the extraction cell following each run to recover any material extracted and subsequently precipitated downstream.

The system was initially tested with organics and water-soluble metal salts. The system operated reliably in these tests. However, difficulties were encountered during the extraction studies on the metal sulfides. Significant deposition occurred in the BPR, which made it difficult to control pressure and maintain flow. The deposition also led to recurring maintenance problems with the BPR.

To circumvent these difficulties and simplify operation, the system was extensively modified; the new design is shown in Figure 1. This design uses a second pump so that fluid and modifier flow can be adjusted independently for better control of modifier addition. The BPR was relocated to serve as an adjustable pressure relief at the outlet of the primary fluid pump. Pressure letdown is achieved with a section of fused silica capillary downstream of the extraction cell. The size of the collection vessel was increased to accommodate insertion of a glass test tube partially filled with dilute nitric acid to collect the extracted material. The end of the capillary is immersed below the liquid level, increasing collection efficiency and reducing the potential for plugging the capillary with deposits formed during final expansion of the fluid. During system modification, the extraction cell sealing characteristics were improved by use of standard double ferrule fittings throughout. Cells of various sizes were used. A typical cell is shown schematically in Figure 2. The cells were constructed of 1/4-in. outside diameter stainless steel tubing ranging from $\sim 1.5$ to $3 \mathrm{in}$. in length. Two major advantages of this design are elimination of the need to flush lines between runs and elimination of contact between the fluid and metallic surfaces downstream of the extraction cell. Because of difficulties in controlling and maintaining the flow of modifier due to limitations of the pump, the second pump was later removed from the system, and the HPLC sample injection valve was used for introduction of modifiers.

The $\mathrm{CO}_{2}$ was delivered as a liquid at pressures ranging from 820 to $1,500 \mathrm{psig}$, depending on ambient temperature and whether an inert gas overpressure was present in the cylinder. The pumphead was cooled to prevent flashing of the fluid in the pump. The system was designed for operation at pressures up to 5,000 psig and temperatures up to $\sim 250^{\circ} \mathrm{C}$. System pressure was maintained by the BPR while flow rate was determined by the operating pressure and capillary. 


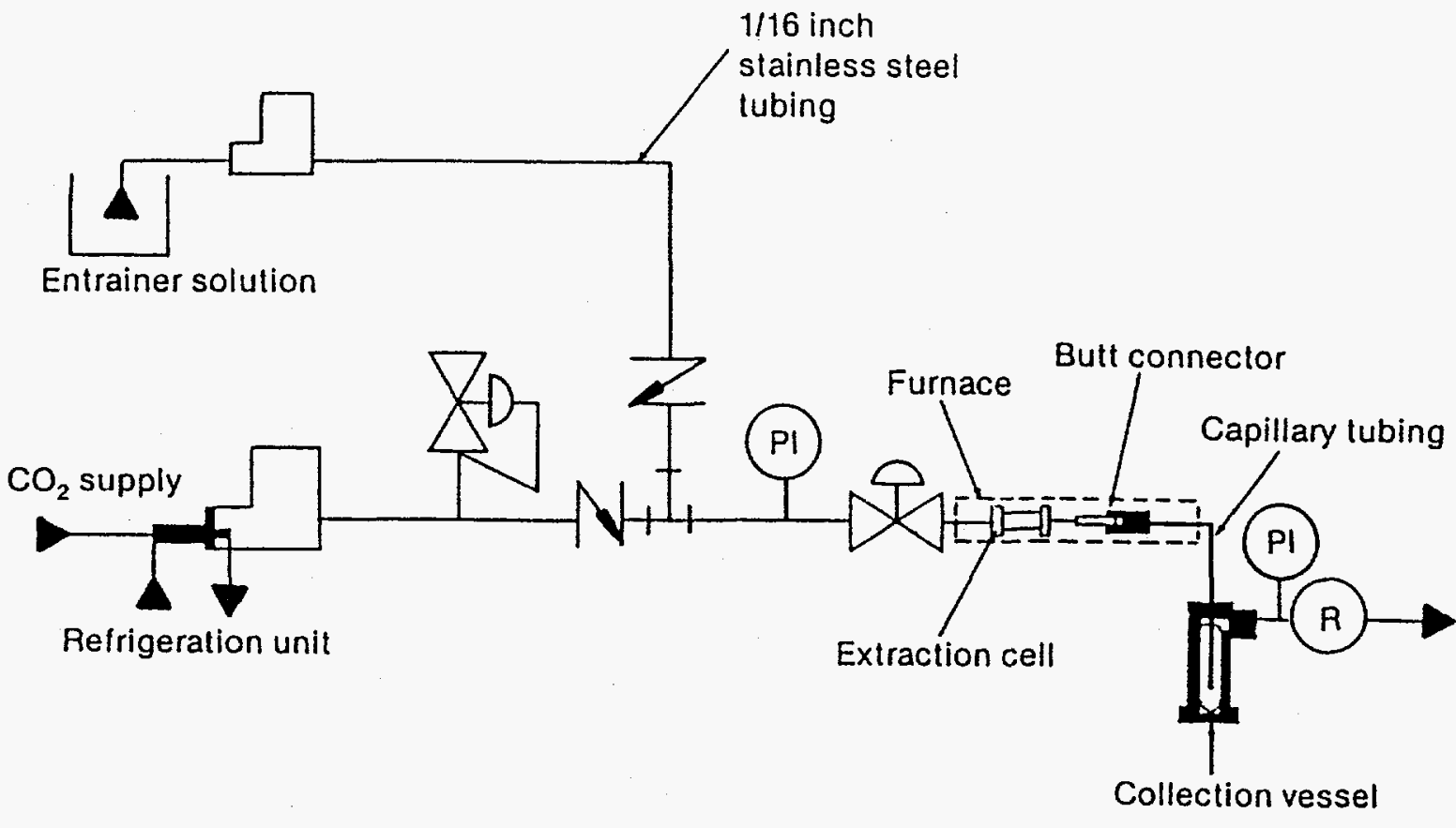

$9 \cdot 4446$

Figure 1. Supercritical fluid extraction system schematic (PI = pressure indicator; $\mathbf{R}=$ rotameter).

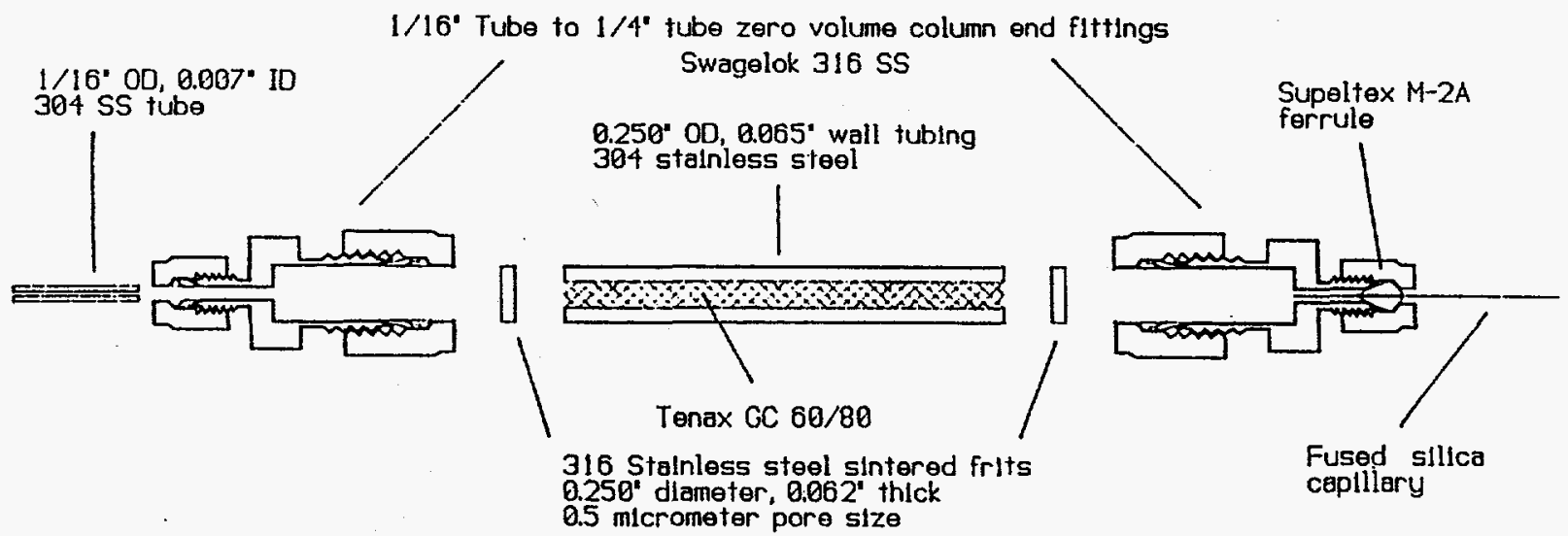

Figure 2. Supercritical fluid extraction cell. 
The cell and capillary were heated by a tube furnace made from a heating tape controlled by an autotransformer; multiple thermocouples along its length monitored extraction temperature.

After placing the cell into the system, it was brought to operating conditions before initiating each run.

Analytical results for the PAHs were obtained by HPLC, while a gas chromatograph equipped with a flame ionization detector was used for analysis of samples from runs that involved the chlorinated hydrocarbons. Analyses for all metal species were performed using an inductively coupled plasma atomic emission spectrophotometer.

Extraction efficiency, defined as the amount of starting material extracted during a run (mg/g fluid), was determined as a function of temperature, pressure, and fluid composition. Prior to system redesign, at the conclusion of each extraction, the system downstream of the extraction cell exit, including the collection vessel, was rinsed with $5 \% \mathrm{HNO}_{3}$; the rinse solution was collected for analysis to determine the amount of the material extracted. Present system design has eliminated the need to flush the downstream lines following each extraction. At the conclusion of each run, the residual material remaining in the cell was also collected for analysis to provide information for calculating material balances and extraction efficiencies.

\section{EXPERIMENTAL RESULTS}

Material balances and extraction efficiencies for the organics were calculated. As expected for the PAHs, extraction efficiencies were found to be inversely proportional to the molecular weight of the compound extracted, ranging from $\sim 95 \%$ for naphthalene, the lowest molecular weight PAH studied, down to $\sim 70 \%$ for pyrene, the highest molecular weight compound. Initial material balances were affected by minor leaks in the system and the relative insolubility of the heavier PAHs in the wash solvents used for rinsing after each run. To alleviate these problems, minor system modifications and changes in operating procedures were made. After these changes, material balances for the PAHs were typically within the range reported above. The liquid organics were easily extracted because of their relatively high vapor pressures. Extraction efficiencies were on the order of 98 to $100 \%$ for all the compounds studied. This behavior was expected based on the similarity in the vapor pressures for all these compounds. Because of inefficient collection of the extracted liquids, not all of the material was recovered. Thus, liquid material balances were lower, in the range of $25 \%$ to $70 \%$.

Similar to the organics discussed above, material balances and extraction efficiencies for the sulfides were calculated from the analytical results and operational data. In each case, the material balance was based on the metallic species and was calculated as the total percentage of the starting material accounted for at the end of a run. Typical material balances were in the range of $80 \%$ or greater. Extraction efficiencies at selected conditions are given in Table 3 . To provide a common basis for comparison in the table, extraction efficiencies have been expressed as milligrams of metal species recovered per gram of carbon dioxide passed through the extraction cell. This mass was calculated from the carbon dioxide flow rate and the length of the extraction. Carbon dioxide flow was based on rotameter reading, corrected for pressure, and converted from volumetric to mass flow. As shown in the table, fluid density at extraction conditions was calculated using a computer algorithm based upon the Law of Corresponding States with the 
Table 3. Extraction efficiencies.

\begin{tabular}{|c|c|c|c|c|c|c|c|c|}
\hline \multirow[b]{2}{*}{ Fluid } & \multicolumn{8}{|c|}{ Extraction Efficiency (mg metal/g fluid) } \\
\hline & As & $\mathrm{Cd}$ & $\mathrm{Co}$ & $\mathrm{Cu}$ & $\mathrm{Pb}$ & $\mathrm{Fe}$ & $\mathrm{Ni}$ & $\mathbf{Z n}$ \\
\hline $\begin{array}{l}\text { Straight } \mathrm{CO}_{2} \\
0.76 \mathrm{~g} / \mathrm{mL}, 71^{\circ} \mathrm{C}\end{array}$ & $7.6 \times 10^{-4}$ & $1.8 \times 10^{-5}$ & $1.1 \times 10^{-5}$ & $1.0 \times 10^{-2}$ & $2.8 \times 10^{-4}$ & $4.2 \times 10^{-4}$ & $1.3 \times 10^{-2}$ & $4.7 \times 10^{-3}$ \\
\hline $\begin{array}{l}\mathrm{CO}_{2}+1 \% \text { Water } \\
0.76 \mathrm{~g} / \mathrm{mL}, 71^{\circ} \mathrm{C}\end{array}$ & $2.1 \times 10^{-3}$ & $3.0 \times 10^{-5}$ & $2.6 \times 10^{-4}$ & $1.7 \times 10^{-3}$ & $1.0 \times 10^{-4}$ & $4.1 \times 10^{-4}$ & $6.8 \times 10^{-3}$ & $1.6 \times 10^{-4}$ \\
\hline $\begin{array}{l}\mathrm{CO}_{2}+1 \% \\
\text { Aqueous EDTA } \\
0.68 \mathrm{~g} / \mathrm{mL}, 75^{\circ} \mathrm{C}\end{array}$ & $6.9 \times 10^{-2}$ & $4.4 \times 10^{-3}$ & $5.3 \times 10^{-2}$ & $1.3 \times 10^{-2}$ & $1.9 \times 10^{-2}$ & $5.6 \times 10^{-3}$ & $1.3 \times 10^{-1}$ & $1.7 \times 10^{-2}$ \\
\hline $\begin{array}{l}\mathrm{CO}_{2}+1 \% \\
\text { Aqueous EDTA } \\
0.99 \mathrm{~g} / \mathrm{mL}, 15^{\circ} \mathrm{C}\end{array}$ & $7.8 \times 10^{-4}$ & $2.8 \times 10^{-3}$ & $4.1 \times 10^{-3}$ & $1.9 \times 10^{-5}$ & $6.7 \times 10^{-4}$ & $6.5 \times 10^{-3}$ & $9.4 \times 10^{-4}$ & $8.9 \times 10^{-4}$ \\
\hline $\begin{array}{l}\text { Water } 0.99 \mathrm{~g} / \mathrm{mL} \text {, } \\
68^{\circ} \mathrm{C}\end{array}$ & $2.4 \times 10^{-2}$ & $1.5 \times 10^{-4}$ & $2.2 \times 10^{-4}$ & $6.2 \times 10^{-5}$ & $2.0 \times 10^{-5}$ & $1.2 \times 10^{-2}$ & $3.2 \times 10^{-4}$ & $1.2 \times 10^{-4}$ \\
\hline $\begin{array}{l}\text { Extraction } \\
\text { Enhancement } \\
\text { Ratio }^{\mathbf{a}}\end{array}$ & 91 & 240 & 4,800 & 1.3 & 68 & 13 & 10 & 3.6 \\
\hline
\end{tabular}

a. Ratio of extraction efficiency with modifier at $75^{\circ} \mathrm{C}$ to that with straight $\mathrm{CO}_{2}$.

compressibility of carbon dioxide calculated using the acentric factor. Neither density nor flow was corrected for the presence of the modifier because of the low percentages involved. Also shown in Table 3 are extraction enhancement ratios, defined as the ratio of extraction efficiency with $1 \%$ aqueous EDTA modifier to that obtained with straight carbon dioxide. This ratio provides a qualitative indication of the improvement in extraction efficiency in comparison to that of the baseline conditions.

In general; measurable extraction and transport of metal species occurred over the range of conditions studied. As an example, the percent of metal transported in the 1-hour run with aqueous EDTA at $75^{\circ} \mathrm{C}$ was

\begin{tabular}{cccccccc}
$\mathrm{As}$ & $\mathrm{Cd}$ & $\mathrm{Co}$ & $\mathrm{Cu}$ & $\mathrm{Pb}$ & $\mathrm{Fe}$ & $\mathrm{Ni}$ & $\mathrm{Zn}$ \\
\hline 11 & 0.40 & 5.1 & 1.2 & 1.4 & 0.50 & 12 & 1.8
\end{tabular}

For most of the metal sulfides studied, extraction efficiency was largely independent of temperature and fluid density over the range of conditions investigated. The only exception was arsenic, whose behavior will be discussed below. However, extraction efficiency is markedly influenced by fluid composition, with the trends varying between the metal species studied. Extraction and transport also occurred under the subcritical conditions studied. Separate runs made under similar conditions showed the same trends in results. 
For the fluids using aqueous modifiers, no significant improvements in extraction efficiency were observed when $1 \%$ water was added to the carbon dioxide, and in some cases, extraction efficiency decreased. On the other hand, the 1\% aqueous EDTA addition resulted in an improvement in extraction efficiency for cobalt of more than three orders of magnitude as indicated by the extraction enhancement ratios. Significant gains were observed for arsenic, cadmium, and lead, while modest improvements were obtained for iron, nickel, and zinc. Copper was essentially not affected. It should be noted, however, that extraction efficiencies for copper and nickel were high overall, with the efficiencies in unmodified carbon dioxide approaching the best ones observed with some of the other metals in $\mathrm{CO}_{2}-1 \%$ aqueous EDTA. The best extraction efficiency $\left(1.3 \times 10^{-1} \mathrm{mg}\right.$ metal/g fluid) was observed for nickel with $\mathrm{CO}_{2}-1 \%$ aqueous EDTA; 12 wt\% of the total sample was transported in a 1-hour run. It is also of interest that modest transport of all the metals was obtained with $\mathrm{CO}_{2}-1 \%$ aqueous EDTA under subcritical conditions. With the exception of iron, extraction efficiencies with $\mathrm{CO}_{2}-1 \%$ aqueous EDTA were higher than those observed with $68^{\circ} \mathrm{C}$ water, where extraction is related to metal sulfide solubility in water at that temperature.

Of all the sulfides studied, only arsenic had an apparent dependence of extraction efficiency on temperature; this dependence is shown in Figure 3a. This trend can be explained by the relatively low melting point $\left(300^{\circ} \mathrm{C}\right)$ of the sulfide, since to a first approximation the solubility of a solid is a function of its melting point, in conjunction with the fact that arsenic does not form a complex with EDTA. Thus, for this cation, the mechanism for dissolution is controlled by solubility, which is proportional to temperature, rather than chelate formation, which is not as sensitive to temperature.

A typical indication of the minor influence of fluid density on extraction efficiency is shown in Figure 3b, in which extraction efficiency is plotted as a function of fluid density for cadmium; similar behavior was also found for lead. The effect of density on extraction efficiency for these two metals was significant only with straight carbon dioxide. Other metals were affected even less.

In the case of straight carbon dioxide, extraction is believed to be based upon solubility and formation of solvated species with $\mathrm{CO}_{2}$. In the case of $\mathrm{CO}_{2}-\mathrm{H}_{2} \mathrm{O}$, the possibility of the formation of carbonic acid, providing an acidic medium to enhance solubilization, was considered. However, under the conditions studied, the fluid exists essentially as a dense gas composed of carbon dioxide containing low concentrations of water in molecular form. Hydronium ions are not present, so the usual concept of $\mathrm{pH}$ is not applicable.

Any increase in solubility noted with the addition of water is probably related to the formation of a more stable hydrated species that enhances dissolution in the fluid. Based upon the observed general lack of enhancement with the water addition, this mechanism is apparently not important. Addition of EDTA, which is a much stronger ligand than either water or carbon dioxide, leads to the formation of more stable metal chelates with a corresponding increase in solubility and extraction as indicated by the respective extraction enhancement ratios.

Similar extraction studies were conducted using methanol and methanolic acetyl acetone (ACAC) as modifiers. Results typical of these studies are shown in Table 4, which also includes extraction enhancement ratios for each metal listed. In this instance, the extraction enhancement 


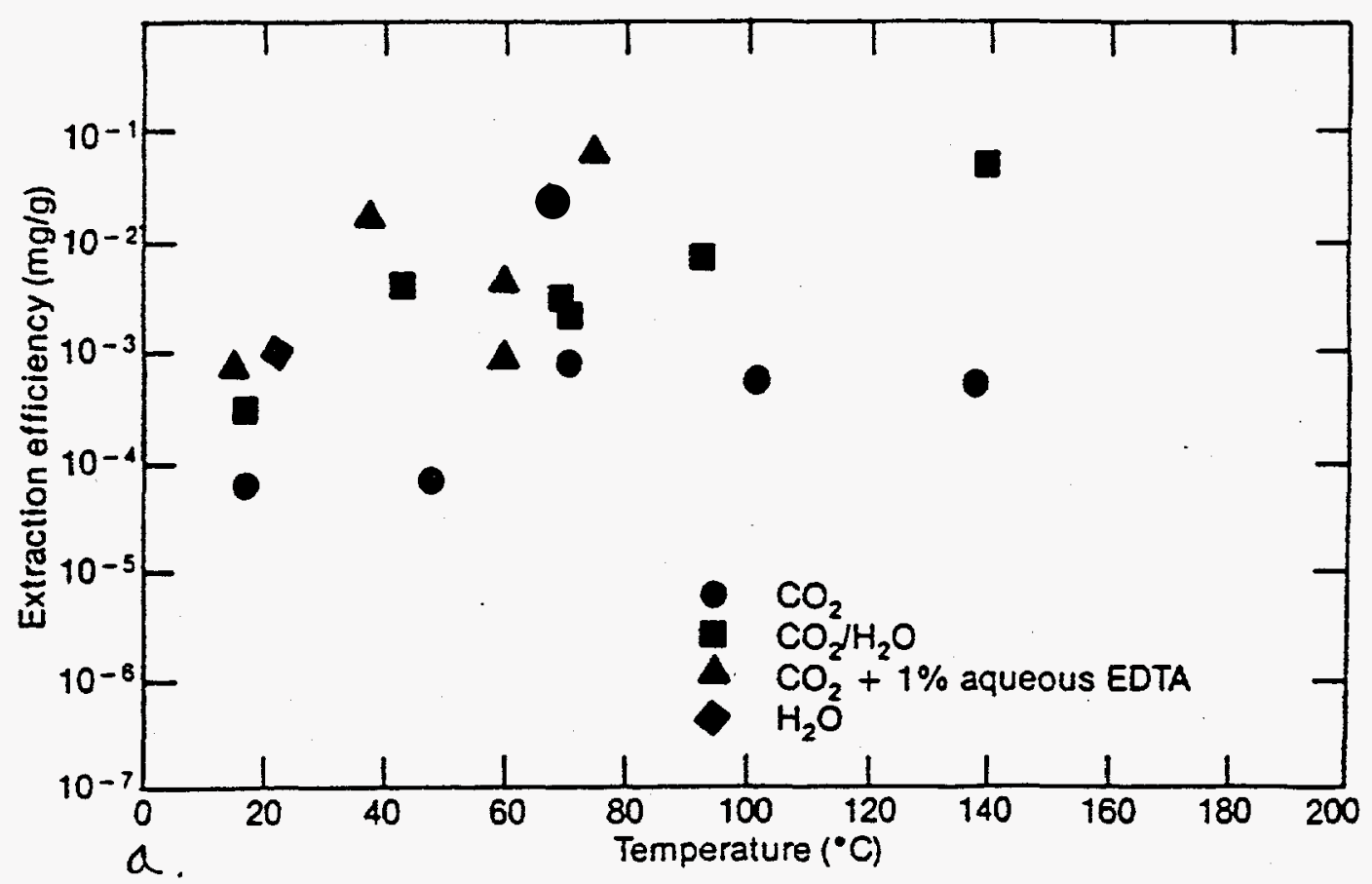

0-4178

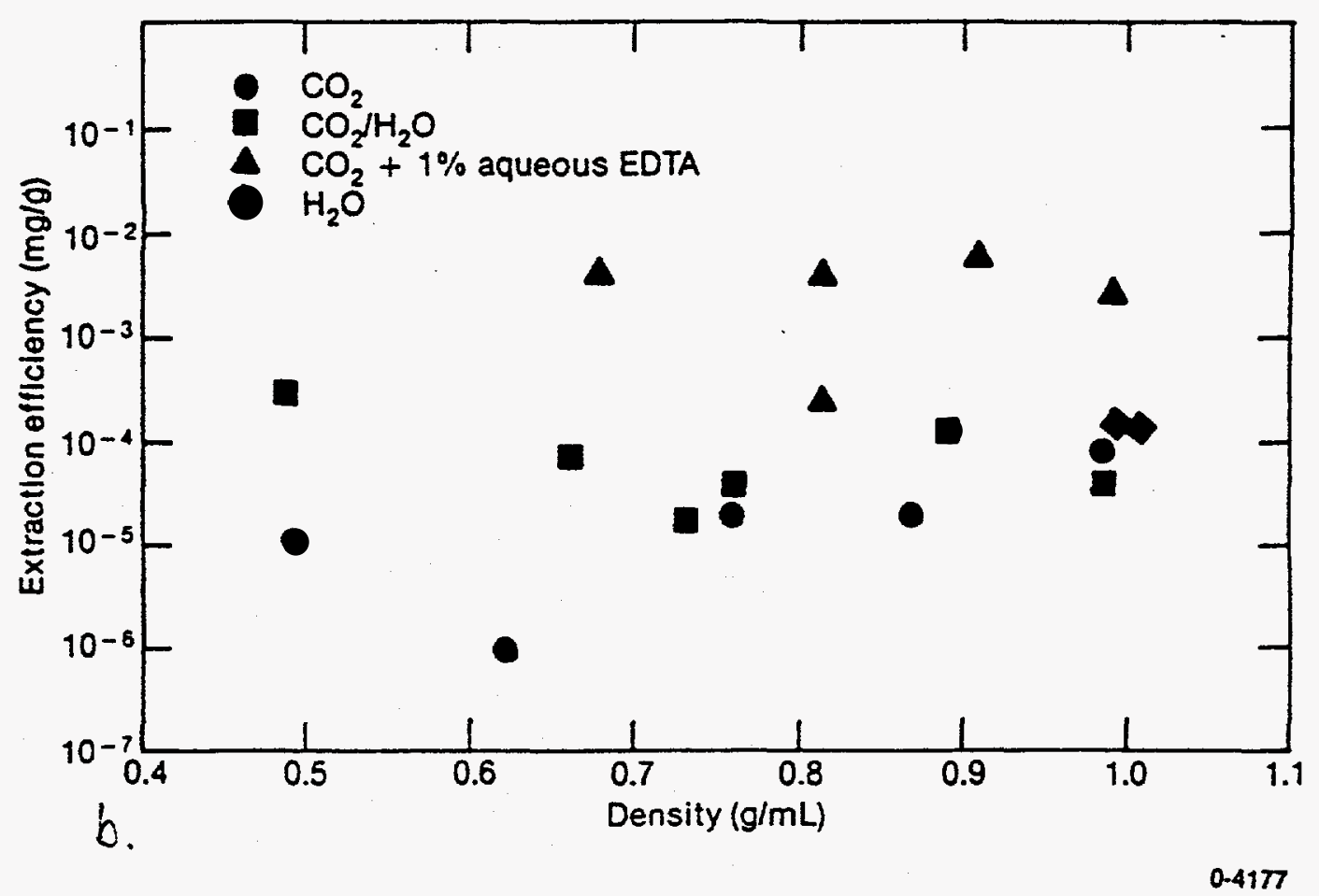

Figure 3. Extraction efficiency as a function of temperature for arsenic (top) and fluid density for cadmium (bottom). 
Table 4. Typical extraction efficiencies for $\mathrm{CO}_{2}$ and $\mathrm{CO}_{2} / \mathrm{MEOH}$ and for $\mathrm{CO}_{2} / \mathrm{MEOH}$ and $\mathrm{CO}_{2} / \mathrm{MEOH} / \mathrm{ACAC}$ at equivalent conditions.

\begin{tabular}{|c|c|c|c|c|c|}
\hline \multirow[b]{2}{*}{ Fluid } & \multicolumn{5}{|c|}{ Extraction Efficiency (mg metal/g fluid) } \\
\hline & As & $\mathrm{Cd}$ & $\mathrm{Co}$ & $\mathrm{Pb}$ & $\mathrm{Fe}$ \\
\hline Straight $\mathrm{CO}_{2}$ & $7.6 \times 10^{-4}$ & $1.8 \times 10^{-5}$ & $1.1 \times 10^{-5}$ & $2.8 \times 10-4$ & $4.2 \times 10^{-4}$ \\
\hline $\mathrm{CO}_{2}+10 \% \mathrm{MEOH}$ & $6.4 \times 10^{-3}$ & $1.1 \times 10^{-3}$ & $6.3 \times 10^{-5}$ & $3.1 \times 10-4$ & $4.7 \times 10^{-3}$ \\
\hline Extraction Enhancement Ratio ${ }^{a}$ & 8.4 & 61 & 5.7 & 1.1 & 11 \\
\hline $\mathrm{CO}^{2} \mathrm{MEOH}$ & $6.4 \times 10^{-3}$ & $1.1 \times 10^{-3}$ & $6.3 \times 10^{-5}$ & $3.1 \times 10^{-4}$ & $4.7 \times 10^{-3}$ \\
\hline $\mathrm{CO} 2 / \mathrm{MEOH} / \mathrm{ACAC}$ & $8.2 \times 10^{-3}$ & $4.0 \times 10^{-3}$ & $5.1 \times 10^{-5}$ & $7.3 \times 10^{-4}$ & $6.3 \times 10^{-3}$ \\
\hline Extraction Enhancement Ratio ${ }^{b}$ & 1.2 & 3.6 & 0.81 & 2.4 & 1.3 \\
\hline
\end{tabular}

ratio is the ratio of extraction efficiency at test conditions to that at specified reference conditions. Methanol gave a modest enhancement of extraction efficiency for the metals studied. This can be ascribed both to the increase in polarity of the fluid produced by the presence of the methanol and the increased solvation and hydrogen bonding afforded by the presence of the methanol. Addition of ACAC produced only negligible changes in extraction efficiency, indicating that the stability of the complexes formed with ACAC as the ligand is not sufficient to significantly enhance extraction efficiency.

In summary, the results obtained show that under supercritical fluid conditions, extraction and transport are enhanced by the addition of modifiers, with the enhancement depending upon the metal. Transport is enhanced in comparison to water under similar temperature conditions, which is significant because of the low levels of modifier added to the supercritical fluid.

\section{DEVELOPMENT OF THEORETICAL BASIS FOR CALCULATING SOLUBILITIES}

To complement the experimental studies, mathematical modeling of various aspects of the supercritical fluid extraction process was undertaken at the University of Idaho. The intent of this work was to provide the capability to predict process performance from a theoretical basis and to help elucidate the mechanisms and fundamental molecular processes of supercritical fluid extraction.

\section{Solubility Calculations}

A program was developed that calculates the solubility of a solid in a supercritical fluid. Solubility of a solute in the vapor or supercritical solvent can be calculated from the system parameters of pressure, temperature, mole volume of the solute, fugacity coefficient of the 
saturated vapor of the pure solute, and the fugacity coefficient of the solute in the vapor or supercritical phase. Usually, the calculation of the fugacity coefficient requires the use of an equation of state (EOS). Numerous cubic equations of state have been proposed in the literature. Though the expressions of the equations differ from each other, in all cases, most of the constants can be calculated from the critical properties of the solute and solvent.

For these studies, a computer program titled Supercritical Fluid Extraction Program (SEMP) was developed for calculating the solubility of a solid solute in a supercritical solvent. The basic theory applied in the program is the Peng-Robinson EOS ${ }^{12}$ in conjunction with Kwak-Mansoori mixing rules. ${ }^{13}$ The program has been expanded to include information on up to 60 solutes using up to 18 characters to identify each substance name. To enhance the data bank of the program, basic information on the chelating agents and their metal-ion chelates was obtained from the literature as available. In addition, predictive methods were also studied because many of the required data are not available in the literature. Specifically, essential data for solubility calculations for a solute include density, vapor pressure, and critical properties.

Solubility of a solid solute, $i$, in a supercritical solvent can be calculated by the following equation: ${ }^{12}$

$y_{i}=\frac{P_{i}^{o}}{P} \frac{\phi_{i}^{o}}{\phi_{i}} \exp \left(\int_{P_{i}^{o}}^{P} \frac{V_{i}^{s}}{R T} d P\right)$

where $y_{i}$ is the solubility in mole fraction of solute $i$ in the vapor or supercritical phase, $P_{i}^{o}$ is the saturated vapor pressure of the solute, $P$ is the system pressure, $\phi_{i}^{0}$ is the fugacity coefficient of the saturated vapor of the solute, $\phi_{i}$ is the fugacity coefficient of the solute in the supercritical phase, $V_{i}^{s}$ is the molar volume of the solute, $T$ is the system temperature, and $R$ is the ideal gas constant.

For a solid solute, $\phi_{i}^{0}$ is usually close to unity because of the small vapor pressure of the solid, and $\mathrm{V}_{\mathrm{i}}^{\mathrm{s}}$ can be regarded as pressure independent because of the incompressibility of the solid. The parameter $\phi_{i}$ can be calculated from the appropriate EOS. Numerous equations of state have been proposed in the literature, including Schmitt-Reid, CCOR, Heyen, Kubi, Kirnik, Harmens-Knapp, Schmidt-Wenzel, Peng-Robinson, Soave, and Redlich-Kwong. When such equations are applied to describe SCF phase behavior, the Peng-Robinson equation has proved to be as good as the other more complicated equations. ${ }^{14}$ This EOS is expressed as ${ }^{12}$

$P=\frac{R T}{(V-b)}-\frac{a}{V(V+b)+b(V-b)}$

where $\mathrm{a}$ and $\mathrm{b}$ are parameters that can be calculated from critical properties. For multicomponent systems, mixing rules are required to determine these parameters for the EOS of the mixture. As an example, consider the classical mixing rules, which were derived from van der Waals' theory. ${ }^{15}$ 


$$
\begin{aligned}
a & =\sum_{i} \sum_{j} x_{i} x_{j} a_{i j} \\
b & =\sum_{i} x_{i} b_{i} \\
a_{i j} & =\left(1-k_{i j}\right)\left(a_{i} a_{j}\right)^{1 / 2}, i \neq j \\
a_{i i} & =a_{i}
\end{aligned}
$$

where $x_{i}$ is the mole fraction of component $i$ in the mixture, $a_{i}$ and $b_{i}$ are the parameters of the EOS for pure $i$, and $k_{i j}$ is the interaction parameter. For the Peng-Robinson EOS, $a_{i}$ and $b_{i}$ can be calculated from the pure component critical properties as follows:

$$
\begin{aligned}
& \mathrm{a}_{\mathrm{i}}=\frac{0.45724 \mathrm{R}^{2} \mathrm{~T}_{\mathrm{ic}}^{2}}{\mathrm{P}_{\mathrm{ic}}}\left[1+\kappa\left(1-\mathrm{T}_{\mathrm{r}}^{1 / 2}\right)\right]^{2} \\
& \mathrm{~b}_{\mathrm{i}}=\frac{0.07780 \mathrm{R} \mathrm{T} \mathrm{T}_{\mathrm{ic}}}{\mathrm{P}_{\mathrm{ic}}}
\end{aligned}
$$

where $k=0.37464+1.54226 \omega-0.26992 \omega^{2}, T_{i c}$ and $P_{i c}$ are the critical temperature and pressure of component $i, T_{r}$ is the reduced temperature $\left(T_{r}=T / T_{i c}\right)$, and $\omega$ is the acentric factor, which was discussed previously.

Finally, $\phi_{i}$, the fugacity coefficient of solute component $i$ in the supercritical phase, can be calculated from the following equation: ${ }^{12}$

$R T \ln \phi_{i}=-\int_{\infty}^{V}\left[\left(\frac{\partial P}{\partial n_{i}}\right)_{T, V, n_{j} \neq n_{i}}-\frac{R T}{V}\right] d V-R T \ln Z$

where $n_{i}$ and $n_{j}$ are the mole numbers of components $i$ and $j$, respectively, and $Z$ is the compressibility factor of the mixture. Further details and discussion of these equations, including additional development of the mixing rules and use of other EOSs, can be found in various sources. $^{12-17}$

In addition to cubic equations of state, other complex equations for calculating solubility were studied. A recently developed theory, Associated Perturbed Anisotropic Chain Theory (APACT), shows promise for predicting the properties of multicomponent systems. The theory, which was derived from statistical mechanics, takes account of molecular motions due to rotational, vibrational, and translational degrees of freedom; anisotropic forces due to dipolar and quadrupolar interactions; and hydrogen bonding due to association between an electron-rich group and an electron-deficient group. Though further improvement is required, APACT's 
reliance on basic molecular properties and the inclusion of the various solute/solvent interactions is an advantage.

As indicated previously, the solubility of a solute can be calculated from first principles using thermodynamic and physical properties such as the critical properties, acentric factors, and solute vapor pressures. For some compounds, these properties are readily available in the literature. In many cases, however, the necessary information is not available so that solubility calculations must rely on the prediction of the essential parameters. One common predictive method is based upon estimation using group contribution techniques. The detailed application of this approach is discussed elsewhere. ${ }^{17}$ This approach can be applied to a broad range of complex organics; Figure 4 presents an example of the theoretical solubilities calculated in this manner compared with published experimental results for the system phenanthrene - carbon dioxide using a molecular interaction parameter $k_{12}$ of $0.126\left(k_{12}\right.$ is $k_{i j}$ of Equation 3). The figure shows good agreement between experiment and theory. The current limitation of this technique is the lack of group contribution data for organometallic moieties.

The new feature of the solubility calculations developed in these studies was the calculation of the molecular interaction parameter from first principles using a group contribution technique. The molecular interaction constant, $\mathbf{k}_{12}$, is an essential parameter for the solubility estimation. No method is available in the literature for its prediction. In fact, $k_{12}$ is usually assumed to be an adjustable parameter with its value determined by trial and error to fit the experimental data. However, when no experimental data are available, $\mathrm{k}_{12}$ remains unknown. In these studies, the relationship between $\mathrm{k}_{12}$ and the molecular structures of the supercritical solvents and solutes was investigated. It has been found that $k_{12}$ values can be related to the contributions from each atom or molecular group fragment of the solute or solvent compounds. A linear correlation between $k_{12}$ and the contributions from a solute is assumed:

$\mathrm{k}_{12}=\mathrm{c}+\sum \Delta_{\mathrm{k}}$

where $\mathrm{c}$ is a constant and $\boldsymbol{\Sigma} \Delta_{\mathrm{k}}$ is the summation of the contributions from each molecular fragment or atom in the compound. This equation applies to mixtures with the same solvent. Table 5 shows $\Delta_{k}$ values for various groups and atoms for the Peng-Robinson EOS when the solvent is carbon dioxide. The parameter $\mathrm{c}$ was found to be 0.0470 . The data used in the regression are from the paper by Haselow et al. ${ }^{16}$ Because of the limited data available, many similar molecular structure groups are assumed to have the same $\Delta_{k}$ values.

Table 6 shows the $\Delta k_{12}$ values estimated by the above method compared to the $k_{12}$ values obtained by the trial-and-error method. ${ }^{16}$ As shown in the table, the difference between the two methods is small, especially when the $k_{12}$ values are large. Also listed is the predicted $k_{12}$ value of cholesterol, 0.206 . Figure 5 is an example of the prediction of the pressure effect on the solubility of cholesterol in carbon dioxide at $310 \mathrm{~K}$. The $\mathrm{k}_{12}$ values used in the figure are 0.166 , 0.206 , and 0.246 . The solubility deviations due to the changes in $k_{12}$ are shown in terms of error bars. Within the low pressure range, the effect of variations in $k_{12}$ on the solubility prediction is small. When the pressure rises, this effect also increases. At $310 \mathrm{~K}$ and 80 bars, for example, the predicted mole fraction solubility of cholesterol in supercritical carbon dioxide varies from $1.34 \times 10^{-2}$ to $1.62 \times 10^{-3}$ when $k_{12}$ changes from 0.166 to 0.246 . 


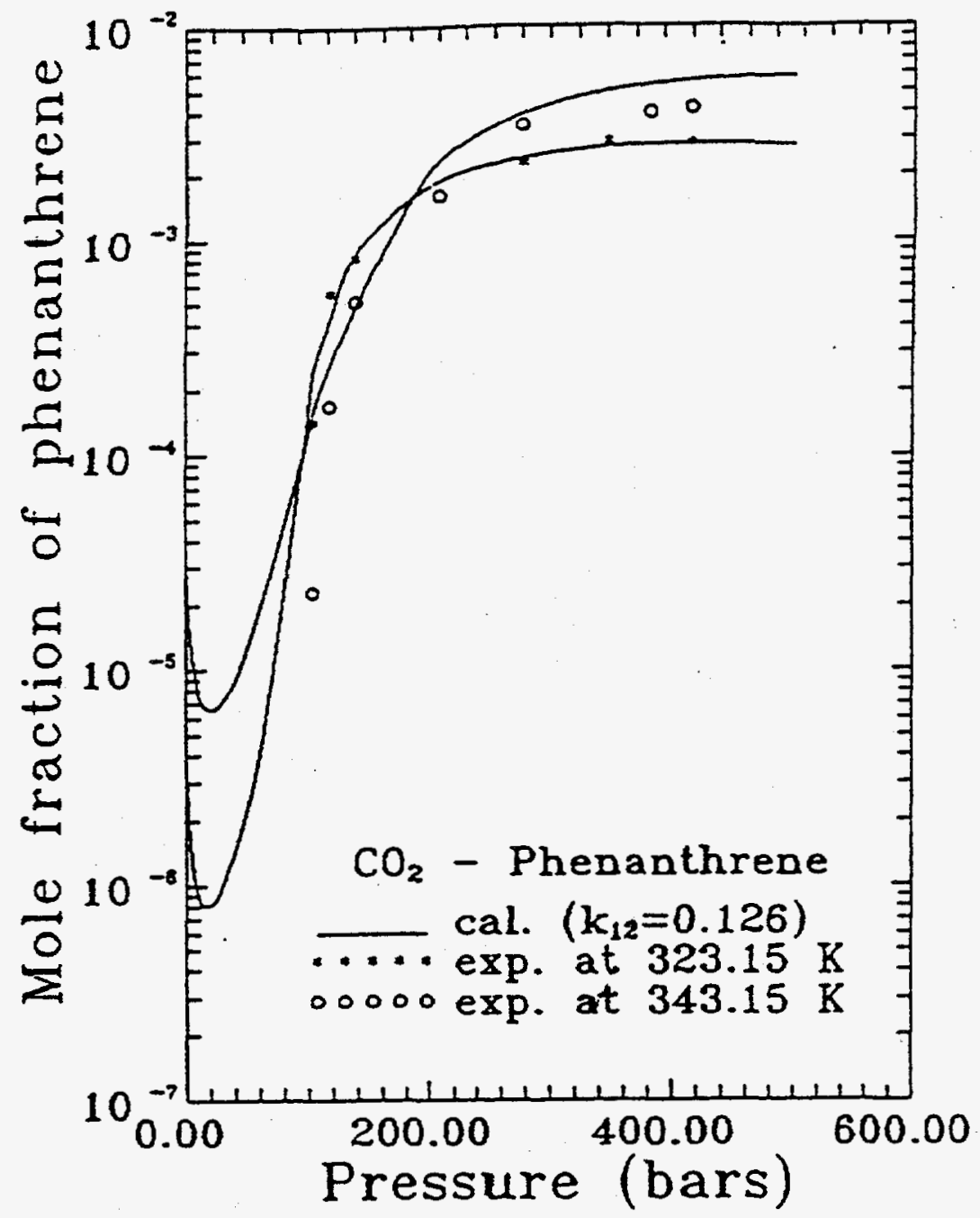

Figure 4. Pressure effects on the solubilities of phenanthrene in carbon dioxide. 
Table 5. Group contributions to interaction constant for organic compound in $\mathrm{CO}_{2}$.

\begin{tabular}{ll}
\hline \multicolumn{1}{c}{ Increments } & $\Delta_{\mathrm{k}}$ \\
\hline Benzene & 0.0100 \\
$-\mathrm{H}$ (replaced from benzene) & 0.0112 \\
$>\mathrm{C}=,-\mathrm{CH}<,-\mathrm{CH}=,>\mathrm{CH}_{2}$ & 0.0027 \\
$-\mathrm{CH}_{3}$ & -0.0038 \\
$-\mathrm{C}_{2} \mathrm{H}_{5}$ & 0.0002 \\
$=0$ & -0.0184 \\
$-\mathrm{OH}$ & 0.0184
\end{tabular}

Note: This table is for the Peng-Robinson EOS only.

Table 6. Estimated $\mathrm{k}_{12}$ values for the Peng-Robinson EOS.

\begin{tabular}{lccc}
\hline \multicolumn{1}{c}{ Solute } & \multicolumn{2}{c}{$\mathrm{k}_{12}$} \\
\cline { 2 - 3 } & Reference 15 & Estimate & $\mathrm{k}_{12}$ Difference \\
\hline Benzoic Acid & 0.0381 & 0.0498 & -0.0117 \\
1,4-Naphthoquinone & 0.0834 & 0.0717 & 0.0117 \\
Phenol & 0.0983 & 0.0866 & 0.0117 \\
Fluorene & 0.1059 & 0.1190 & -0.0131 \\
2,6-dimethylnaphthalene & 0.1108 & 0.1120 & -0.0012 \\
2,3-dimethylnaphthalene & 0.1132 & 0.1120 & 0.0012 \\
Naphthalene & 0.1146 & 0.1196 & -0.0050 \\
Triphenylmethane & 0.1195 & 0.1178 & 0.0017 \\
Hexaethylbenzene & 0.1257 & 0.1257 & 0.0000 \\
Phenanthrene & 0.1284 & 0.1263 & 0.0021 \\
Pyrene & 0.1658 & 0.1632 & 0.0026 \\
Cholesterol & -- & 0.2061 & -- \\
\hline
\end{tabular}




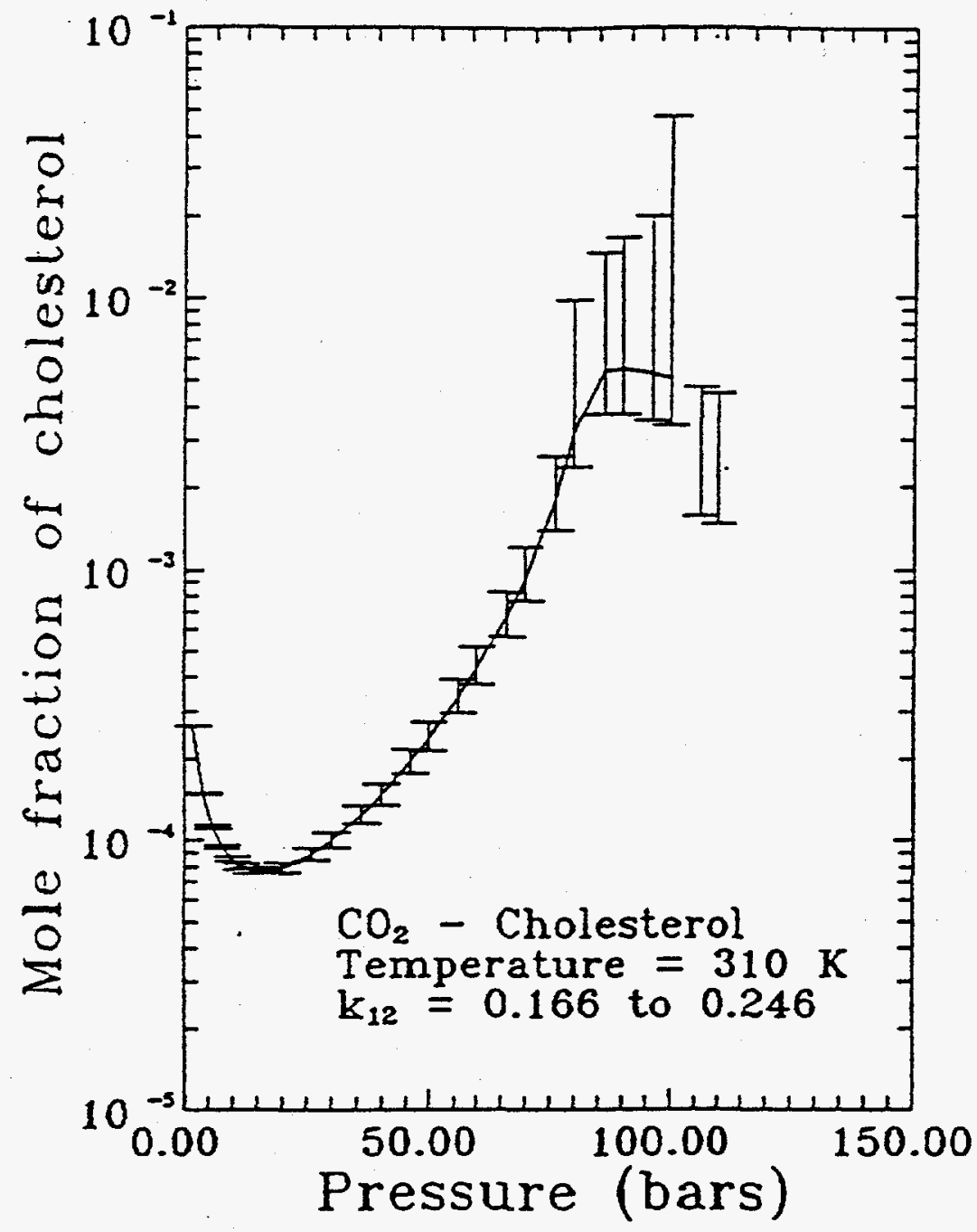

Figure 5. Prediction of the pressure effect on the solubility of cholesterol in carbon dioxide. 
In summary, these studies have shown that the solubility of a solute in a supercritical solvent can be predicted from fundamental data such as normal boiling points, molecular weights, and molecular structures. The accuracy of the solubility prediction depends largely on the availability of essential data such as critical temperatures and pressure, acentric factors, solute vapor pressure, and solute/solvent molecular interaction constants. An interaction constant significantly affects the reliability of the prediction results. The best way to obtain an interaction constant is by trial and error. The estimation of an interaction constant based on molecular structure is an alternative when no experimental data are available. The results of the estimation are at least semiquantitative. However, applying these techniques to the calculation of solubilities of inorganics and organometallics, such as chelates, is not possible at this time because of the lack of information in the literature on the essential parameters necessary for these predictions for these classes of materials, namely either the basic thermodynamics and physical properties listed previously or suitable group contribution factors.

\section{Extraction Simulation}

Mathematical modeling of leaching of metals or organic compounds from a packed column under supercritical conditions was conducted. The fluid-particle mass transfer coefficient, longitudinal dispersion, intraparticle diffusion, and solute distribution coefficient have been taken into account. It was assumed that a column was packed with solute-containing particles and that the eluant was a pure supercritical solvent. It was also assumed that the solubility of solute in the solvent was finite. Applying the Laplace transform method, the exact solution of the model was obtained. The solution is an expression of an infinite integral of an exponentially decaying function and a periodic sine function of system parameters (such as Peclet number and Biot number).

Specifically, the model considers an SCF extraction system for which the SCF is generated and then passed through a column packed with porous particles (e.g., a soil that contains specific solutes). After extracting solute from the particles, the SCF exits the column. In the context of the model, the SCF can be either a supercritical mixture of carbon dioxide and cosolvent or of carbon dioxide, chelating agent, and cosolvent. It is assumed that:

1. The porous particles are small in comparison to the overall bed height, and the bed is macroscopically uniform in void fraction.

2. The fluid velocity profile is uniform or flat; therefore, the solute concentration in the fluid is uniform in the same cross section.

3. The longitudinal dispersion coefficient $\left(D_{L}\right)$ is independent of the total column length, and the effective intraparticle diffusion coefficient $\left(D_{e}\right)$ is constant and independent of concentration.

4. Local extraction equilibrium at any solid-fluid interface (internal or external) is attained so rapidly that it is effectively independent of time.

5. The change of fluid density over the length of the column is negligible.

6. The temperature is constant throughout the column. 
Based on these assumptions, the following differential equations are applicable to the system:

$$
\begin{aligned}
& \frac{\partial C}{\partial t}+u \frac{\partial C}{\partial z}-D_{L} \frac{\partial^{2} C}{\partial z^{2}}=R_{P} \\
& \frac{\partial W}{\partial t}=D_{e} \frac{1}{r^{2}} \frac{\partial}{\partial r}\left(r^{2} \frac{\partial W}{\partial r}\right)
\end{aligned}
$$

where $\mathrm{C}\left(\mathrm{mol} / \mathrm{m}^{3}\right)$ is the concentration of solute in the bulk fluid, $\mathrm{W}\left(\mathrm{mol} / \mathrm{m}^{3}\right)$ is the total internal concentration in the particles, $\mathrm{z}(\mathrm{m})$ is the distance in the flow direction, $\mathrm{r}(\mathrm{m})$ is the radial distance from the center of a spherical particle, $t(\mathrm{~s})$ is time, $u(\mathrm{~m} / \mathrm{s})$ is the average superficial velocity, $D_{e}\left(\mathrm{~m}^{2} / \mathrm{s}\right)$ is the diffusivity in the fluid inside the particles, $D_{L}\left(\mathrm{~m}^{2} / \mathrm{s}\right)$ is the longitudinal dispersion coefficient, and $R_{p}\left(\mathrm{~mol} / \mathrm{m}^{3} \mathrm{~s}\right)$ is the production rate of a solute in the fluid.

The initial and boundary conditions for solving the above equations can be regarded as:

$$
\mathrm{C}(\mathrm{z}, \mathrm{O})=\mathrm{C}_{\mathrm{o}}
$$

$\mathrm{C}(\mathrm{O}, \mathrm{t})=\mathbf{0}$

$\partial C(\infty, t) / \partial z=0$

$\mathrm{W}(\mathrm{z}, \mathrm{r}, \mathrm{O})=\mathrm{W}_{\mathrm{o}}$

$\left[\frac{\partial W}{\partial R}\right]_{r=0}=0$

where $C_{0}\left(\mathrm{~mol} / \mathrm{m}^{3}\right)$ is the initial concentration in the fluid and $\mathrm{W}_{0}\left(\mathrm{~mol} / \mathrm{m}^{3}\right)$ is the initial concentration in the particles.

The production rate, $R_{p}$, is due to the solute being extracted in the particles and then diffusing from the porous particles to the outside fluid. In Equation (7), $R_{p}$ is

$R_{p}=-\left(\frac{1-\epsilon}{\epsilon} \frac{3 k_{f}}{R}\right)\left(C-w_{f}\right)$

where $\epsilon$ is the void-volume fraction of the packed column, $\mathrm{k}_{\mathrm{f}}(\mathrm{m} / \mathrm{s})$ is the mass transfer coefficient for transfer from the particle surface to the fluid in the particle pores, $R(\mathrm{~m})$ is the particle radius, and $w_{f}$ is the concentration of solute in the fluid within the particle pores.

The model treats organic and inorganic solutes separately. The case of organic solutes is developed on the assumption of a rapid, simple equilibrium between the concentration of organic in the solid and the concentration of organic dissolved in the fluid contained within the pores of 
the particles. For inorganics, the system considered is the extraction of a cation from a solid matrix by a ligand that forms a metal chelate. This case assumes similar rapid equilibrium, in this instance involving as reactants the solid cation and the unionized ligand with the metal chelate and other cations as products. The assumption of equilibrium in conjunction with the particle porosity can be used to eliminate $w_{f}$ from the expression for $R_{p}$ in Equation (14), replacing it with an expression involving the time-dependent surface concentration of solute in the particles as follows:

$$
R_{p}=-\frac{(1-\epsilon)}{\epsilon} \frac{3 k_{f}}{R}\left(C-\frac{W(z, R, t)}{\epsilon_{p}+\left(1-\epsilon_{p}\right) / K}\right)
$$

where $\epsilon_{\mathrm{p}}$ is the particle porosity, $\mathrm{K}$ is the distribution coefficient, which is the ratio of concentration of solute in the particle pore fluid to the concentration in the solid, and $W(z, R, t)$ is the solute surface concentration for the particles.

A solution of Equation ( 8 ) in terms of particle surface concentration can be obtained by established techniques. ${ }^{18}$ This solution is then used to calculate $\mathrm{R}_{\mathrm{p}}$. Applying the Laplace transform method, $W(z, R, t)$ can be eliminated from Equation (15), leading to the exact solution of the model.

A personal computer program was developed to conduct the numerical evaluation of the model. The input parameters of the program include the system temperature and pressure, column length, flow rate, and particle size. The program outputs are an elution curve (concentration versus time) and a recovery curve (total recovery of the solute versus time). The program can be used not only for fitting the experimental data but also for predicting unknown elution curves under various assumed conditions. The expression of the solution contains an oscillatory integrand. The period of oscillation is a function of the system parameters and the elution time. Numerical simulations of the effects of the parameters on elution have been conducted and are reported in detail elsewhere. ${ }^{19}$

The conclusions from the modeling and numerical simulation are, first, that there is at least qualitative agreement between the model and similar models developed to elucidate packed column chromatography or elution from packed beds reported in the literature. Secondly, there is also qualitative agreement between the numerical simulation and experimental results for similar studies reported in the literature. Finally, extraction is a function of both the operating conditions and physical properties of the fluid, as would be intuitively anticipated.

\section{CONCLUSIONS}

- The scientific feasibility of extraction and transport of selected cations by supercritical carbon dioxide-based fluids has been confirmed.

- For most metals studied, use of a modifier enhances extraction efficiency. Enhancement factors range from less than 1.0 to 4,800 depending on conditions, modifier, and metal. 
- Transport is also observed at near-critical conditions.

- Depending on the conditions and metal, transport of up to $12 \%$ of the starting material has been observed.

- Transport in modified carbon dioxide is significantly higher than in water at the same temperature.

- The mechanism of extraction varies. For some cations, it appears to depend upon the formation and stability of the complex formed. In other cases, extraction appears to depend on the solubility of the material itself.

- Aqueous EDTA is the best modifier studied; however, it is likely that there are other chelating agents that would be as good or better.

- Observed extraction efficiencies for inorganics do not approach those typical for organics under similar conditions.

- The solubility of an organic solute in a supercritical fluid solvent has been successfully predicted from fundamental data.

- A molecular interaction constant for organic solutes has been successfully estimated from fundamental molecular data.

- The supercritical fluid extraction process has been modeled mathematically and the dependence on system parameters demonstrated in simulations. 


\section{REFERENCES}

1. M. A. McHugh and V. J. Krukonis, Supercritical Fluid Extraction Principles and Practice, Butterworths, Boston, MA, 1986, p. 507.

2. P. Hubert and D. G. Vitzthum, "Fluid Extraction of Hops, Spices, and Tobacco with Supercritical Gases," in Extraction with Supercritical Gases, edited by G. M. Schneider, E. Stahl and G. Wilke, Verlog Chemie, Deerfield Beach, FL, 1980, pp. 25-43.

3. K. M. Dooley, R. Gambrell, and F. C. Knopf, "Supercritical Fluid Extraction and Catalytic Oxidation of Toxic Organics from Soils," in Land Disposal, Remedial Action, Incineration and Treatment of Hazardous Waste: Proceedings of the Thirteenth Annual Research Symposium at Cincinnati, OH, May 6-8, 1987, EPA/600/8-87/015, U.S. EPA, July 1987, pp. 373-381.

4. B. O. Brady, C.-P. C. Kao, K. M. Dooley, F. C. Knopf, and R. P. Gambrell, "Supercritical Extraction of Toxic Organics from Soils," Industrial and Engineering Chemistry Research, 26, 2, February 1987, pp. 261-268.

5. B. O. Brady, C-.P. C. Kao, R. P. Gambrell, and F. C. Knopf, "The Use of Entrainers in the Supercritical Extraction of Soils Contaminated with Hazardous Organics," Industrial and Engineering Chemistry Research, 26, 10, October 1987, pp. 2058-2062.

6. M. Modell, G. G. Gaudet, M. Simson, G. T. Hong, and K. Diemann, "Destruction of Hazardous Waste Using Supercritical Water," in Incineration and Treatment of Hazardous Waste: Proceedings of the Eighth Annual Research Symposium at Ft. Mitchell, KY, March 810, 1982, EPA-600/9-83-003, U.S. EPA, 1982, pp. 202-212.

7. C. K. Rofer, Kinetics Experiments and Bench-Scale System: Background, Design, and Preliminary Experiments, LA-11106-MS, DOE/HWP-41, Los Alamos National Laboratory, September 30, 1987, 33 pp.

8. C. A. Eckert, G. W. Leman, J. F. Brennecke, and S. R. Alferi, "Supercritical Solvent Extraction," in Land Disposal, Remedial Action, Incineration and Treatment of Hazardous Waste: Proceedings of the Thirteenth Annual Research Symposium at Cincinnati, OH, May 68, 1987, EPA/600/9-87/015, U.S. EPA, July 1987, pp. 366-372.

9. F. R. Groves, Jr., B. Brady, and F. C. Knopf, "State-of-the-Art on the Supercritical Extraction of Organics from Hazardous Wastes," CRC Critical Reviews in Environmental Control, 15, 3, 1985, pp. 237-274.

10. R. C. Reid, J. M. Prausnitz, and B. E. Poling, The Properties of Gases and Liquids, 4th Ed., McGraw-Hill Book Company, New York, 1987, pp. 121-136.

11. Ibid, pp. 23-24. 
12. M. A. McHugh and V. J. Krukonis, Supercritical Fluid Extraction Principles and Practice, Butterworths, Boston, MA, 1986, pp. 79-95.

13. G. A. Mansoori, "Mixing Rules for Cubic Equations of State," in Equations of State Theories and Applications, edited by K. C. Chao and R. L. Robinson, Jr., ACS Symposium Series No. 300, Washington, DC: American Chemical Society, 1986, pp. 314-330.

14. J. F. Brennecke and C. A. Eckert, "Phase Equilibria for Supercritical Fluid Process Design," AIChE Joumal, 35, 9, September 1989, pp. 1409-1427.

15. E. H. Benmekki, T. Y. Kwak, and G. A. Mansoori, "Van der Waals Mixing Rules for Cubic Equations of State," in Supercritical Fluids Chemical and Engineering Principles and Applications, edited by T. G. Squires and M. E. Paulaitis, ACS Symposium Series No. 239, Washington, DC: American Chemical Society, 1987, pp. 101-114.

16. J. S. Haselow, S. J. Han, R. A. Greenkorn, and K. C. Chao, "Equation of State for Supercritical Fluid Extraction," in Equations of State Theories and Applications, edited by $\mathrm{K}$. C. Chao and R. L. Robinson, Jr., ACS Symposium Series No. 300, Washington, DC: American Chemical Society, 1986, pp. 156-178.

17. S. Huang, Studies of Corrosion and Extraction in Supercritical Fluids, Ph.D. dissertation, University of Idaho, Moscow, ID, October 1990, pp. 119-146.

18. H. S. Carslaw and J. C. Jaeger, Conduction of Heat in Solids, 2nd Ed., Clarendon Press, Oxford, 1986, p. 233.

19. J. Huang, ibid, pp. 147-164. 